\title{
Georeferencing Brazilian Highway Addresses
}

\author{
Sandro Laudares, Mateus Pereira Libório, Marianna Petrovna Ekel \\ Pontifícia Universidade Católica de Minas Gerais (PUC-MG), Belo Horizonte, Brazil \\ Email:m4th32s@gmail.com
}

How to cite this paper: Laudares, S., Libório, M.P. and Ekel, M.P. (2016) Georeferencing Brazilian Highway Addresses. Journal of Geographic Information System, 8, 547-557. http://dx.doi.org/10.4236/jgis.2016.85046

Received: July 25, 2016

Accepted: October 15, 2016

Published: October 18, 2016

Copyright $\odot 2016$ by authors and Scientific Research Publishing Inc. This work is licensed under the Creative Commons Attribution International License (CC BY 4.0).

http://creativecommons.org/licenses/by/4.0/

\section{(c) (i) Open Access}

\begin{abstract}
The usage of georeferencing as a search tool has suffered a massification after the diffusion of technologies developed by Google and Microsoft. In this context, problems related to the location of properties situated on highways are becoming quite usual in Brazil, because properties registration in highway is permitted in the country and this invalidates the dynamics of the georeferencing process. Therefore, a growing number of geotechnology users which desire to localize properties on highways, find inaccurate or amiss geographical information. This research focus is to present an enumeration method for highway properties and, consequently, the possibility of a precise georeferencing. The presented method contributes to turning possible the precision of this georeferencing process and it will also be relevant for geotechnology diffusion considering its integration to geographic information systems which include geocoding tools.
\end{abstract}

\section{Keywords}

Geoprocessing, Georeferencing, Highways, Geographic Precision

\section{Introduction}

The location of a place of interest is useful to decision making due to three factors: the probability of having in it goods or services that are seeking, the level of mobilized resources that favors the search for these goods and services and the situation in which the author is assigned [1].

The need of location is a constant demand since the beginning of humanity. Human being is always looking for shelter, food and other points of his own interest. People are increasingly depending on georeferencing [2]. However, the obstacles in describing the point of interest during the georeferencing process impact on the amount and the quality of geographical information and, specially, it is important to note that it impacts on a large number of datasets geocoding cases [3]. 
The georeferencing methods are, currently, trying to overcome a set of problems, as following 1) text without geographic coordinates; 2) inconsistent formatting and misspellings; 3) vacuous, inaccurate, confused or contradictory descriptions [4] [5]. The existence of these problems precludes the correct usage of maps and their application, interposing the advance of its dissemination [6].

The reader will find in this article the fundamentals for the highway properties location problem comprehension and the importance of its solution. In some studies, results presented in digital maps analysis associated to georeferencing confirm problems related to places location in maps [2]-[5] [7]-[9].

The incorrect location of a point of interest can, oftentimes, imply in serious damage [10] because companies, governments and the digital society are adapted to maps usage and frequently use them in supporting and guidance of their trade, political or movable actions [2]. Furthermore, the digital cities dynamics and the cheapening of transport costs modified the distance perception and approximated people [11]. It contributed for the highway longitudinal densification, which is a result of private interest in economical exploitation of the highway infrastructure, considering the catalyzing disposition of the economic development [12]. This work proposes a set of procedures to find highway properties. Therefore, the following goals were outlined: 1 ) identify the failures in the existing tools [5];2) verify mistake standards [9]; 3) propose the best solution for the problem [13]. The disposition of the work happens in the following way: introduction, theoretical research framework, methodology, and final consideration.

\section{Theoretical Framework}

Geography is a combined mathematical science which aim is to explain earth properties as dimensions, the movements, celestial phenomena and it parts through quantification and regional, political and social description and also habits description of the nations which live in the earth [14].

Quantitative geography emphasizes spatial analysis techniques and geostatistics [15]. The geographical quantification, according to Figure 1, represents trades of theories

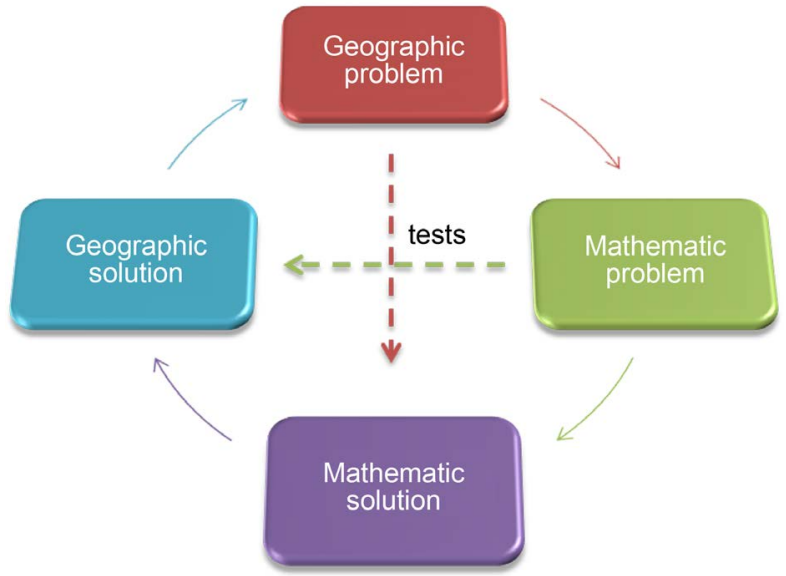

Figure 1. Sciences dealing [16]. 
and concepts among the mathematical and the geographical science, presenting a formal, clear and coherent language to explain an idea [16].

The geographical quantification together with the internet advances and the development of standardized systems of easy usability reappointed the way that geographic space is thought through geotechnologies and geoprocessing [2].

Geotechnologies are the vehicle of technologies associated to geosciences in the process of providing conditions for the geographic usage in other knowledge areas, being constituted by hardware, software and people integration and also by tools as: geographic information systems; remote sensing; and global positioning systems [17].

Geotechnology is constituted by several different types of knowledge which aims the study of phenomenological interactions evidenced in society and the environment. Geotechnology uses geoprocessing tools of geographical science which combines a set of manipulation, analysis and visualization of records techniques through maps [18].

In this context, georeferencing is dominated also as a technique for the process of linking and adjustments of spatial data to a known coordinates system [18]. This process is constituted by descriptive texts conversion in points of reliable coordinates and is called georeferencing. The process of conversion, correctly implemented, increases information precision, turning them analytically useful [4].

Georeferencing is a simple process. In each block of the city, a street is represented by a line showed in the table and is also represented on the map as a table line (ex. Table 1).

The line contains information about the street such as street name, final and initial enumeration, even and odd side, and city name, represented, in this case by Betim City, Minas Gerais State, in Brazil (Figure 2).

In the process of searching an exact street, its name can be identified in the table, turning possible the process of localizing the required address according to its numerical correspondence. The user searching for an exact location identifies the line segment

Table 1. Digibase data basis [19].

\begin{tabular}{|c|c|c|c|c|c|}
\hline \multirow{2}{*}{ Street Name } & \multicolumn{4}{|c|}{ Address numbering } & \multirow{2}{*}{ City } \\
\hline & From left & From right & To left & To right & \\
\hline Amazonas street & 1 & 2 & 499 & 500 & Betim \\
\hline Amazonas street & 501 & 502 & 999 & 1000 & Betim \\
\hline Amazonas street & 1001 & 1002 & 1499 & 1500 & Betim \\
\hline Amazonas street & 1501 & 1502 & 1999 & 2000 & Betim \\
\hline Amazonas street & 2001 & 2002 & 2499 & 2500 & Betim \\
\hline Amazonas street & 2501 & 2502 & 2999 & 3000 & Betim \\
\hline BR 381 & 0 & 0 & 0 & 0 & Betim \\
\hline BR 381 & 0 & 0 & 0 & 0 & Betim \\
\hline BR 381 & 0 & 0 & 0 & 0 & Betim \\
\hline BR 381 & 0 & 0 & 0 & 0 & Betim \\
\hline
\end{tabular}




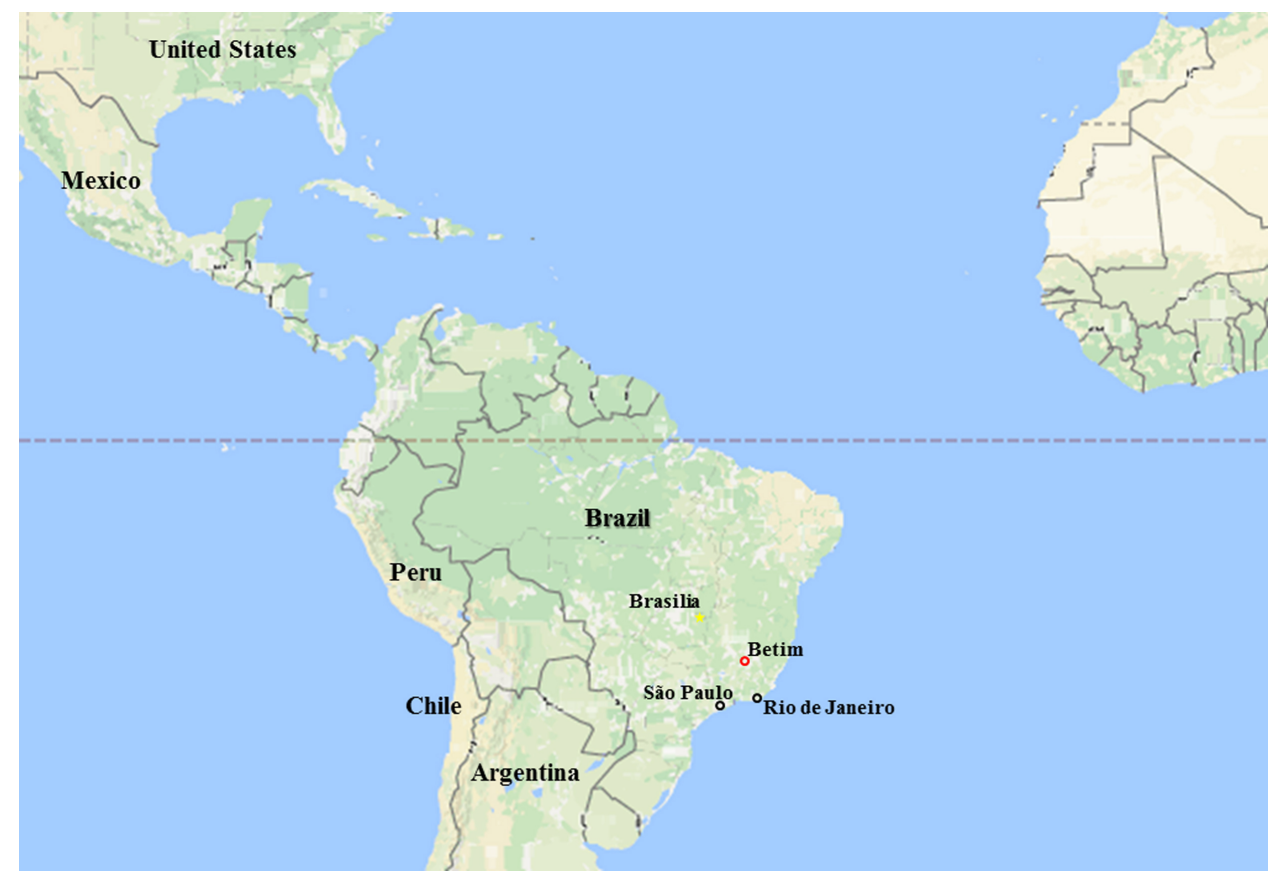

Figure 2. Study area: Betim-MG, Brazil.

through it numerical correspondence. That numerical correspondence is obtained through linear interpolation, according to [8].

Georeferencing method will present positive results when the line segments record is precise. Those records are generally produced through data collect of each block. Nevertheless is common to find out inconsistencies in the properties numerical register and these inconsistencies impact on the georeferencing quality [5].

The problem of dealing with highways is vaster. The highway is a highroad which, having its platform rightly prepared and paved, is designated to the motor vehicles movement [20], but in Brazil highways, the location number is not something mandatory as shown in Table 1 . The absence of the property number will preclude the obtainment of geographic coordinates. A kilometer mark, normally used in highways, can include a lot of properties, generating erroneous information to the geotechnology user [6]. The causing factor of the problem was observed in the absence of relevant informations in the description or identification and is possible to say that the comprehension of the problem and the actions to be taken to solve this problem require highway location (see Figure 3).

The problem is easily perceived when five addresses in the highway BR-381 are georeferenced and at the place that the numbers 150 and 1500 appear at the top right, the numbers 15 and 2500 in the center and the number 150,000 at the left, showing clearly the location mistakes. These mistakes happen because of the lack of highway numbers according to Table 1. Considering the dissipation of addresses, the losses related to an improper displacement can be perceived at the position of distance at $75.2 \mathrm{~km}$ between the georeferenced points.

As well as in the Brazilian case, United States north numbering and naming highway 


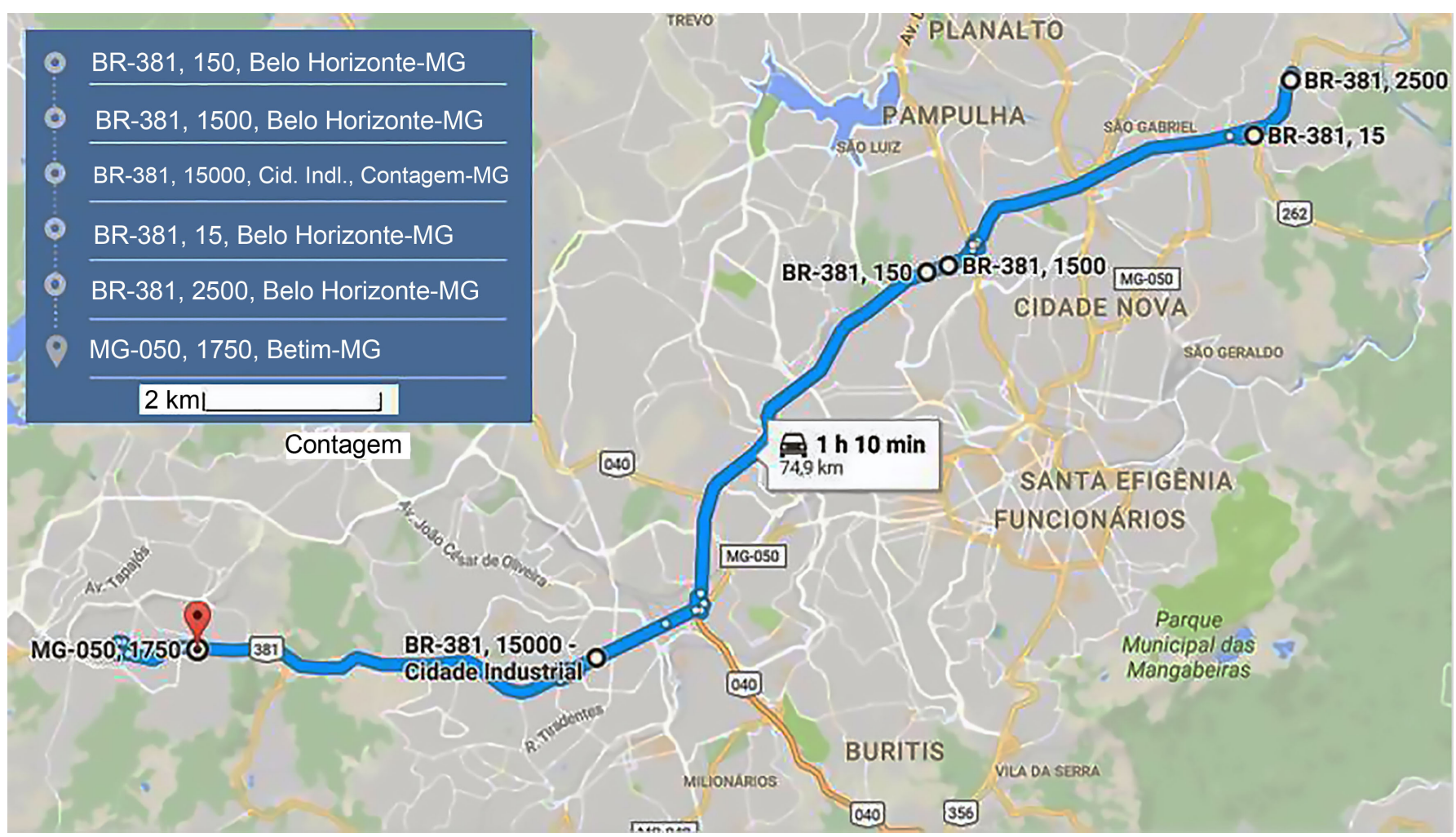

Figure 3. Highway georeferencing failures presented in details.

system is another example of the hindrance in highway georeferencing, because many American highways are not straight and do not follow, perfectly, a pointed direction by it numeration and its names and numbers change during the time [4].

The Tulane University, New Orleans-United States of America, developed a georeferencing tool which observes the set of problems that occurs during the process of coordinates extraction and location, pointing out the mistakes level on georeferencing system and its name is GEOLocate [21].

GEOLocate tool operates with small or big data sets combining elements belong to the georeferencing process in a single product. GEOLocate provides automated georeferencing by allotment and unit manual. The tool permits latitude and longitude coordinates extraction, classifying the precision of registers which are georeferenced [21].

In this article, the developed solution is integrated to geographic information systems which have geocoding tools. Considering this fact, the purposed method can be automatized through geographic information systems, helping it usage and dissemination. Furthermore, the method is adaptable to another road types which present enumeration problems and, consequently, also georeferencing problems. Comprehensively, the method can be applied to several situations, in which is necessary to geo-reference railways, waterways or dirt roads as well.

\section{Material and Methods}

The solution formulation is described in three steps. The first step is the highway data- 
base creation; the second one is the application of the mathematic-geographical function for properties numbering allocation; and the third step is focused on the properties located on highway for numbering and georeferencing. Chart 1 presents the detailed catenation of these steps.

Highway database creation step: the analysis happened through official agencies constituted by three data sources and it adherence to georeferencing method by line segment. The first option was the creation of highway axes by remote sensing which uses images extracted from satellite images from the Brazilian institute of spatial surveysINPE; the second option was to do the database adaptation of the Brazilian national department of transport infrastructure-DNIT; the third option was the highway letters usage from the Brazilian institute of geography and statistics-IBGE.

The axes lines of DNIT are more precise when obtained by satellite images treatment and its scale 1:150,000 is also more accurate than the IBGE one, fact that is verified

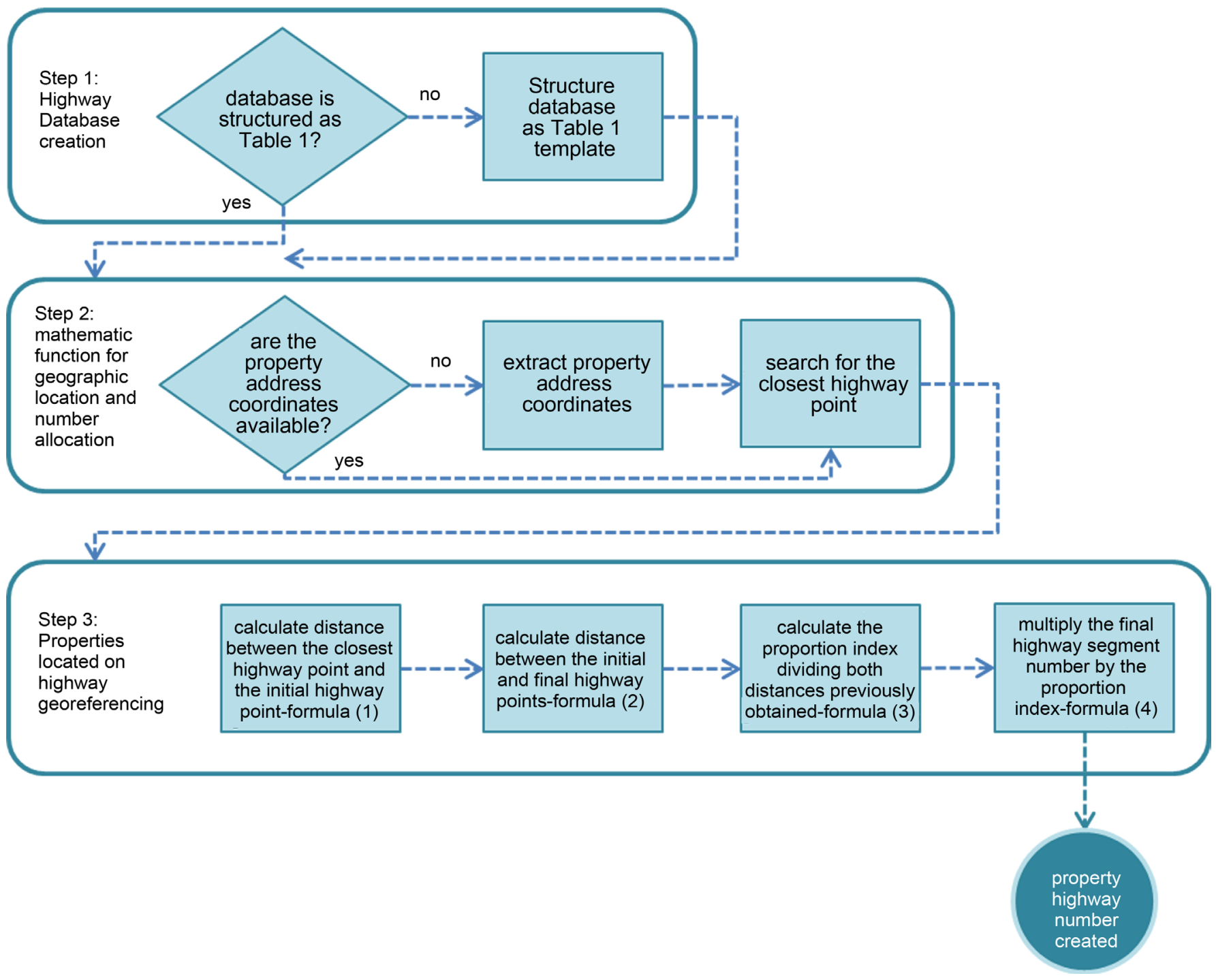

Chart 1. Methodological workflow chart. 
perceiving the overlap of these maps over the satellite images. Highways on DNIT basis are, as opposed to the IBGE ones, segmented in parts linked with the highway name, the initial and final kilometer as well as with the segments sizes in meters (see Table 2). The presence of these information on that database determined the choice as the proposal solution of the problem.

The reconstruction of highway spatial data (Table 2) according to what is presented on Table 1 enable the usage of georeferencing method aiming the second step of solution in localizing highway properties.

Mathematic function for geographic location and numbering allocation step: the employed technique, through Quantum GIS software, was the reverse geocoding. The reverse geocoding enumerates and determinates the point of interest with name and number of the location according to the latitude and longitude of this location [15]. The reverse geocoding is a service which transforms an exact coordinate geographic position in a normalized description defined by location name and number [22].

The location designation occurs through research of the highway line axe closer to the intended point and through information extraction of location name involved in highway addresses data basis. The number is calculated from the coordinate pair above the highway line axe closer to the desirable location. The point above the line axe is metrically proportional about segment measure and, by following; it related initial and final numbers (right and left). The reverse geocoding is presented in Figure 4, or in the set of mathematical equations from (1) to (4).

The segment size determined by its correspondent point is represented as $A \times 111$ (see [24] for further comprehension), the whole segment size, given by the initial and final points, is represented as $B \times 111$ and the percentage fraction, given by segment $A$ quotient in relation to segment $B$, representing the $\Delta_{x \%}$. Then, multiplying the number of the final kilometer in the highway segment, called here $F_{k m}$ by $\Delta_{x \%}$ the precise addresses number is found, where:

Table 2. DNIT data basis structure [23].

\begin{tabular}{cccccc}
\hline $\begin{array}{c}\text { Highway } \\
\text { Name }\end{array}$ & State & Length $(\mathrm{km})$ & Situation & Initial Km & Final Km \\
\hline BR 317 & Acre & 14,600 & Paved & 198.2 & 212.8 \\
BR 364 & Acre & 94,900 & Paved & 179.4 & 274.3 \\
BR 317 & Acre & 39,300 & Paved & 29.4 & 68.7 \\
BR 364 & Acre & 45,900 & Paved & 53.3 & 99.2 \\
BR 317 & Acre & 1500 & Paved & 292.1 & 293.6 \\
BR 364 & Acre & 18,000 & Planned & 789.7 & 807.7 \\
BR 317 & Acre & 12,000 & Paved & 225.4 & 237.4 \\
BR 364 & Acre & 60,800 & Paving works & 386.3 & 447.1 \\
BR 364 & Acre & 4200 & Implanted & 544 & 548.2 \\
BR 317 & Acre & 3300 & Paved & 182.3 & 185.6 \\
\hline
\end{tabular}




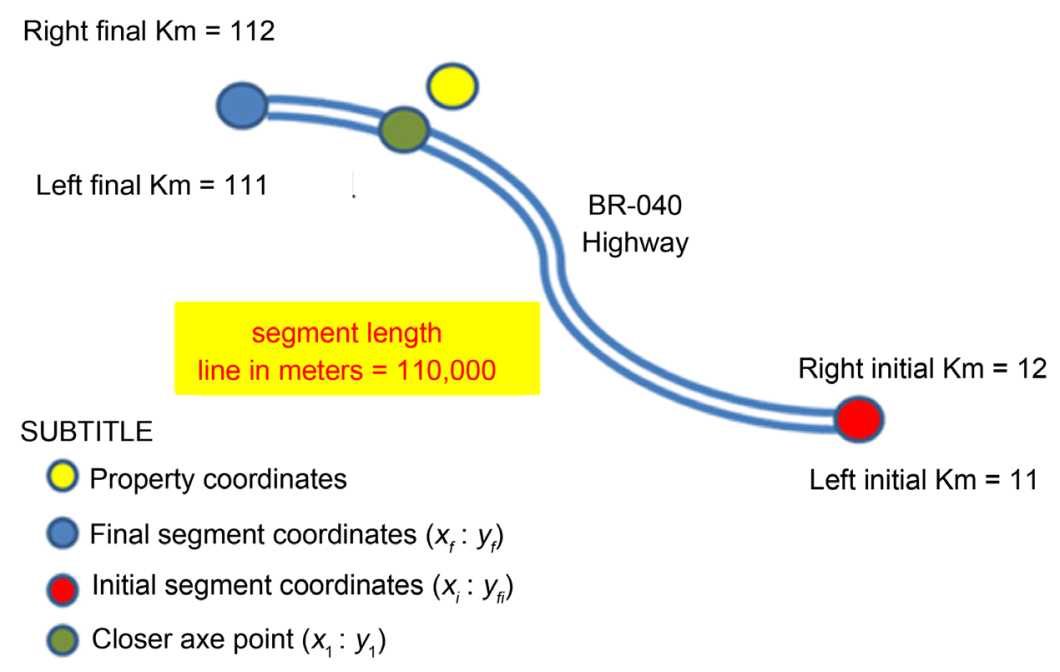

Figure 4. Reverse geocoding scheme.

$$
\begin{aligned}
& A=\sqrt{\left(X_{i}-X_{1}\right)^{2}+\left(Y_{i}-Y_{1}\right)^{2}} \\
& B=\sqrt{\left(X_{i}-X_{f}\right)^{2}+\left(Y_{i}-Y_{f}\right)^{2}} \\
& \Delta_{x \%}=\frac{A}{B} \\
& n_{x}=F_{k m} \times \Delta_{x \%}
\end{aligned}
$$

As the yellow point (Figure 4) is at the even side, it is necessary to round up the number to the nearest even number, otherwise, round it up to the nearest odd number. At this time, the proposed method creates as result a "new" complete address. It occurs because its enumeration is generated by the presented geographic-mathematic model. After coordinates edification register or property positioned in a highway the geotechnology user will be able to spread its "new" address with a number that, when georeferenced, will point out for the desired location.

\section{Results}

The prepared results are based on addresses searches simulations. The simulation presented in Figure 5 represents the point of interest of a highway described as BR 381, number 10.

The application of the set of proposed geographic-mathematical equations generated the following solution:

$$
\begin{aligned}
& A=\sqrt{\left(X_{i}-X_{1}\right)^{2}+\left(Y_{i}-Y_{1}\right)^{2}} \rightarrow 4815 \\
& B=\sqrt{\left(X_{i}-X_{f}\right)^{2}+\left(Y_{i}-Y_{f}\right)^{2}} \rightarrow 20514 \\
& \Delta_{x \%}=\frac{A}{B} \rightarrow \frac{4815}{20514} \rightarrow 23.47 \% \\
& n_{x}=F_{k m} \times \Delta_{x \%} \rightarrow 4814
\end{aligned}
$$




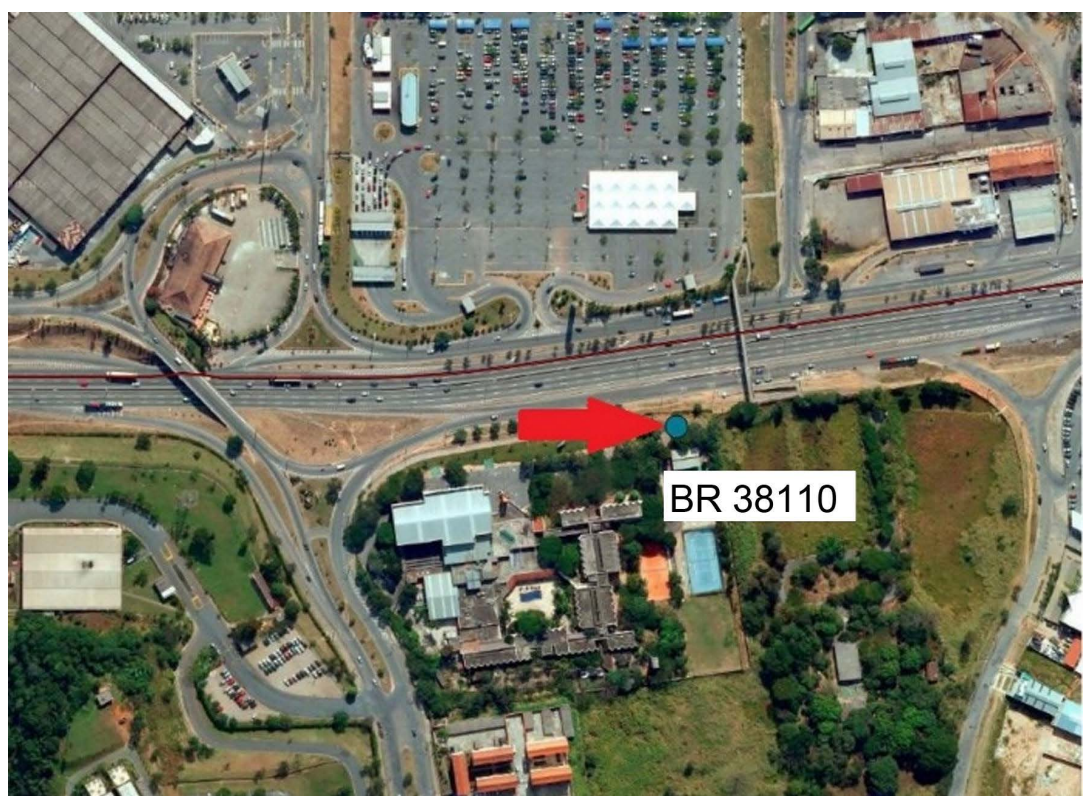

Figure 5. Solution simulation in a point of interest.

The point is at the left side, so the result should be round up for an even number and, because of this fact, the obtained address is BR-381, number 4814 . This released result was again georeferenced with the "new" property number, generating the same coordinate pair of the original data. Because of that, the georeferencing which uses this method will give to the user always the same coordinate related to the indicated geographic location of the property owner, in other words, the exact geographic point according to the location of interest.

\section{Results Discussion}

An analysis composed by thirty simulations which creates the addresses is presented, in a short way, in Table 3. The coordinates obtained through Google Maps are not reflected on the enumeration ordinal positioning so, in other words, they present a georeferencing failure. The enumeration created by the proposed method showed the right addresses with enumeration planning, making possible the process of correcting the highway georeferencing failure in all cases analyzed.

The problem solution following quantitative geographical techniques was capable to be proven and demonstrated in a detailed and clear way.

\section{Conclusions}

The employed method to the solution of georeferencing failures in highways has shown to be effective, able to be disseminated, of low cost and accessible to a large number of users.

Geoprocessing and geotechnology as a common factor in nowadays society demand corrective actions, which has been presented in this work. These actions contribute to the unanimous diffusion of geographic technologies, favoring everyone who uses it and needs to look for residence addresses or economic activities along highways. 
Table 3. Simulations results.

\begin{tabular}{ccc}
\hline Searched address & Proposed method numbering & Google Maps numbering \\
\hline BR 381-Point 1 & 4811 & 10 \\
BR 381-Point 2 & 4318 & 50 \\
BR 381-Point 3 & 4318 & 30 \\
\hline
\end{tabular}

Using the presented method will favor society by making access and information to certain points of highways easier. The benefits of this solution can also be used in transports and resources optimization, field of knowledge that has been using GPS technologies to the control of field teams, sales, maintenance and others which depend on the location of points of interest while exerting social, governmental and economical activities.

\section{References}

[1] Bourdin, A. (2001) A questão local. DPeA Editora, Rio de Janeiro.

[2] Laudares, S. (2014) Geotecnologia ao alcance de todos. Appris, Curitiba.

[3] Edwards, S.E., Strauss, B. and Miranda, M.L. (2014) Geocoding Large Population Level Administrative Datasets at Highly Resolved Spatial Scales. Transactions in GIS, 18, 586-603. http://dx.doi.org/10.1111/tgis.12052

[4] Murphey, P.C., et al. (2004) Georeferencing of Museum Collections: A Review of Problems and Automated Tools, and the Methodology Developed by the Mountain and Plains SpatioTemporal Database-Informatics Initiative (Mapstedi). Phyloinformatics, 1, 1-29.

[5] Duncan, D.T., et al. (2011) Evaluation of the Positional Difference between Two Common Geocoding Methods. Geospatial Health, 5, 265-273. http://dx.doi.org/10.4081/gh.2011.179

[6] Zandbergen, P.A. (1995) Influence of Street Reference Data on Geocoding Quality. Geocarto International, 26, 35-47. http://dx.doi.org/10.1080/10106049.2010.537374

[7] Skaba, D.A., et al. (2004) Geoprocessamento dos dados da saúde: O tratamento dos endereços. Caderno Saúde Pública, Rio de Janeiro, 20, 1753-1756. http://dx.doi.org/10.1590/S0102-311X2004000600037

[8] Quesada, J.A., Nolasco, A. and Moncho, J. (2013) Comparación de lasaplicaciones de Google y Yahoo para lageocodificación de direccionespostalescon fines epidemiológicos. Revista Española de Salud Pública, 87, 201-206. http://dx.doi.org/10.4321/S1135-57272013000200009

[9] Strickland, M.J., et al. (2007) Quantifying Geocode Location Error Using GIS Methods. Environ Health, 6, 1-8. http://dx.doi.org/10.1186/1476-069x-6-10

[10] Brandão, M. and Abreu, J.F. (2003) Deslocamento, tempo e dinheiro: Uma análise exploratória de convergência espacial. Geografia, modelos de análise espacial e GIS. Editora PUCMINAS.

[11] Ribeiro, W.C. (2015) Relação espaço/tempo: Considerações sobre a materialidade e dinâmica da história humana. Terra Livre, 4, 39-54.

[12] Pereira, L.A.G. and Lessa, S.N. (2011) O processo de planejamento e desenvolvimento do transporte rodoviário no Brasil. Caminhos de Geografia, 12.

[13] Horanont, T., et al. (2014) Space Profile-Based Reverse Geocoding Service Using Cloud Platform. IEEE International Conference on Services Computing, 27 June-2 July 2014, 842- 
843. http://dx.doi.org/10.1109/scc.2014.116

[14] de Moraes, A.C.R. (1989) A sistematização da Geografia Moderna: In A gênese da geografia moderna. Ed. Hucitec, São Paulo, 15-25.

[15] Bailey, T.C. and Gatrell, A.C. (1995) Interactive Spatial Data Analysis. Vol. 413, Longman Scientific \& Technical, Essex.

[16] Capel, H. (1981) El curso de lasideas científicas: Tercera parte in Filosofia y Ciência enla Geografia Contemporânea. Barca Nova, Espanha, 245-509.

[17] Rosa, R. (2011) Geotecnologias na geografia aplicada. Revista do Departamento de Geografia, 16, 81-90.

[18] Fitz, P.R. (2008) Geoprocessamento sem complicação. Oficina de Textos, São Paulo.

[19] Digibase (2014) Mapas Digitais. http://digibase.com.br/novo/area.php?area=mapasdigitais

[20] Brasil, D.N.E.R. (1997) Glossário de Termos Técnicos Rodoviários. Divisão de Capacitação Tecnológica, Rio de Janeiro, 296.

[21] Rios, N.E. (2014) GEOLocate: A Platform for Georeferencing Legacy Collection Data. GSA Annual Meeting, Vancouver.

[22] Bychowski, T., et al. (2003) Open Geospatial Consortium Inc.

[23] Brasil, D.N.I.T. (2016) Atlas e Mapas: Shapefiles. http://dnit.gov.br/mapas-multimodais/shapefiles

[24] Menezes, P.M.L. and Couto, F.M. (2016) Roteiro de cartografia. Oficina de Textos.

Submit or recommend next manuscript to SCIRP and we will provide best service for you:

Accepting pre-submission inquiries through Email, Facebook, LinkedIn, Twitter, etc.

A wide selection of journals (inclusive of 9 subjects, more than 200 journals)

Providing 24-hour high-quality service

User-friendly online submission system

Fair and swift peer-review system

Efficient typesetting and proofreading procedure

Display of the result of downloads and visits, as well as the number of cited articles

Maximum dissemination of your research work

Submit your manuscript at: http://papersubmission.scirp.org/

Or contact jgis@scirp.org 